\title{
Nonunion of Bone
}

National Cancer Institute

\section{Source}

National Cancer Institute. Nonunion of Bone. NCI Thesaurus. Code C118392.

The permanent failure of bone to heal, commonly due to a fracture or an osteotomy. 